\title{
Functional differentiation of adjunctive drinking and wheel running in rats
}

\author{
JOHN PENNEY and JONATHAN SCHULL \\ Reed College, Portland, Oregon 97202
}

\begin{abstract}
Food-deprived rats were exposed to a schedule in which a brief stimulus was presented approximately once every $60 \mathrm{sec}$. The first leverpress to occur in the presence of the stimulus always turned it off, and produced a food pellet $50 \%$ of the time. When the rats were given concurrent access to water, a running wheel, or both, drinking predominated during intervals initiated by pellet delivery, while running predominated during intervals initiated without food. When allowed to obtain all of their food pellets at the beginning of a session, rats drank less and ran more than when the intermittent schedule was in effect, and most drinking occurred within the first half of the session, while running was distributed throughout the session. Adjunctive drinking and wheel running appear to be functionally different, drinking being schedule-induced and food-bound, running being neither.
\end{abstract}

In 1971, Falk suggested that the conditions under which a variety of schedule-related activities occur are the same and that these activities might therefore be subsumed in a new class of adjunctive behavior, whose members "yield similar dynamic properties and are functions of the same variables" (p. 579). Falk urged that his hypothesis be evaluated by observing the extent to which experimental manipulations have similar effects upon the proposed members of the class. Some such comparisons have been attempted, and the results have generally been interpreted as demonstrating the viability of the proposed class. However, closer examination of the nature of these comparisons shows such a conclusion to be questionable at best. In this paper, we will show that many "adjunctive" activities yield different dynamics, and argue that these differences are functionally significant.

A major source of confusion has been the lack of attention given the problem of the commensurability of various response measures used to assess the "strengths" of different activites. For example, one of the characteristics of adjunctive behavior is supposed to be the existence of an "effective range" of consummatory rates which facilitate adjunctive activities: Measures of schedule-induced polydipsia

\footnotetext{
Very special thanks are due Dr. Allen J. Neuringer, who provided the inspiration and the laboratory space. Colleen Kelly and Deborah Porter helped to conduct the research. Jim Kalat, Richard Katzev, Allen Neuringer, Richard L. Solomon, and J. E. R. Staddon provided valuable comments and criticism. Preparation of the manuscript was supported by National Science Foundation Grant GB-31125X to J. E. R. Staddon, principal investigator. Reprints may be obtained from John Penney, Department of Psychology, Duke University, Durham, North Carolina 27706. Jonathan Schull is now at the Department of Psychology, University of Pennsylvania.
}

(Falk, 1966; Flory, 1971), schedule-induced aggression (Flory, 1969), and schedule-induced escape (Brown \& Flory, 1972) have all been shown to increase as rates of food delivery are increased to some intermediate value (roughly between 15 and 30 presentations/h), and thereafter to decrease as food rates are further increased. Escape and aggression were measured in response/minute. Polydipsia, however, was defined as the amount of water ingested per unit of food delivered. The amount of food delivered per session was held constant, such that the length of a session, and consequently the amount of time available per session within which to drink, was directly proportional to the rate of food delivery. Hence, the decreases in water ingestion reported at relatively high food rates may simply reflect temporal constraints on drinking. Staddon (1977) transformed both Falk's and Flory's data to reflect amount of water ingested per unit time and found that this measure increased monotonically with increasing food rates over the entire range investigated in these two studies. Similar results have been reported by other investigators (Hawkins, Schrot, Githens, \& Everett, 1972; Segal, Oden, \& Deadwyler, 1965). Furthermore, Staddon (1977) reported that the overall rate of wheel running decreases monotonically as food rates are increased from $2045-\mathrm{mg}$ pellets/h to 12 pellets $/ \mathrm{min}$. Thus, as the rate of food delivery is increased, the rate of drinking increases monotonically, rates of aggression and escape vary bitonically, and the rate of wheel running decreases monotonically. These activities do not yield similar dynamic properties as a function of this manipulation.

Another source of confusion has been the variety of apparatus used in different laboratories, which often produce different results. For example, King (1974), Levitsky and Collier (1968), and Segal (1969) 
all report that wheel running by rats is a scheduleinduced activity that occurs at higher rates when an intermittent schedule of reinforcement is in effect than when such a schedule is discontinued. However, Skinner and Morse (1957) and Staddon and Ayres (1975) found no facilitation of wheel running by intermittent schedules. These different results may be due to the fact that in the Levitsky and Collier and the King studies rats were confined to a running wheel, while in the studies reporting no schedule induction rats responded for food in a separate chamber from which they had access to a running wheel. If wheel running is determined not to be schedule induced, then it is differentiable from other adjunctive behavior by yet another manipulation.

The present experiment demonstrates that various measures of drinking and wheel running evince different dynamics when rats leverpress for food which is omitted on $50 \%$ of all trials.

\section{METHOD}

\section{Subjects}

Four male Long-Evans rats, approximately 80 days old at the beginning of the experiment, were maintained at $80 \%$ of their free-feeding weight by food deprivation. Each experimentally naive animal weighed between 250 and $300 \mathrm{~g}$ before deprivation, and each was individually housed with water available ad lib in home cages.

\footnotetext{
Apparatus

The test chamber was an oblong cage, $12.5 \mathrm{~cm}$ high, $15 \mathrm{~cm}$ wide, and $25 \mathrm{~cm}$ long, mounted on an activity wheel support structure. The floor and end walls of the cage were made of galvanized wire $(1.3 \mathrm{~cm}$ grid). One of the side walls was a hinged sheet of metal which served as the door of the cage. The other side wall was also of sheet metal, with a sliding panel that allowed access to a running wheel $36 \mathrm{~cm}$ in diameter with a running surface $10.5 \mathrm{~cm}$ across.

A $2.5 \times 5 \mathrm{~cm}$ metal food cup was mounted on the floor in one corner of the cage, and a metal response lever, $5 \mathrm{~cm}$ wide $\times 1.2 \mathrm{~cm}$ thick, was mounted $6.5 \mathrm{~cm}$ above the level of the floor. A removable drinking tube was mounted approximately $.8 \mathrm{~cm}$ outside the opposite end of the cage, $6.5 \mathrm{~cm}$ above the level of the floor. A rat could drink by sticking its snout through the wire grid; in doing so, the animal's tongue completed a drinkometer circuit used to measure licks. Thus, the cage arrangement was such that when a rat was stationed at the response lever, the food cup was to his left, the door to the running wheel was to his right, and the drinking tube was directly behind him.

A number of devices were mounted on the running wheel support structure above the cage. An automatic pellet dispenser
}

was used to deliver standard $45-\mathrm{mg}$ Noyes rat pellets to the food cup. A white 7-W lamp was attached to the underside of the feeder, approximately $15 \mathrm{~cm}$ above the response lever and $5 \mathrm{~cm}$ above the roof of the cage. This light was visible inside the cage or the running wheel, and it served as a discriminative stimulus. A smaller $2-\mathrm{W}$ lamp was mounted on the running wheel axle, $7.5 \mathrm{~cm}$ above the center of the cage. This lamp provided general chamber illumination and was also used to operate a photocell whenever the running wheel completed a quarter turn. The entire apparatus was placed inside a wood sound-attenuating chamber. The reinforcement schedule was arranged by standard electromechanical equipment located in an adjoining room.

\section{Procedure}

Preliminary training was conducted in a standard single-lever operant chamber (Physiological Electronics No. 800). After the rats were trained to press the response lever for food, they were given light-dark discrimination training whereby each leverpress produced a food pellet when the houselight was on, but never produced a pellet when the houselight was off. The animals were then habituated to the experimental chamber during two 1-h sessions on successive days, while the running wheel and drinking tube were accessible and no food was presented.

The experiment was conducted in six phases, during which the animals were exposed to four experimental conditions. The sequence of conditions and number of sessions of exposure given each rat are summarized in Table 1. During Phases I, II, III, IV, and VI, the discriminative stimulus was presented approximately once every $60 \mathrm{sec}$. A single response in the presence of the stimulus turned it off and initiated a new $60-\mathrm{sec}$ interval, but such responses produced a food pellet only $50 \%$ of the time. Interval outcome was randomized with the constraint that no more than three reinforced or unreinforced intervals could occur in succession.

During Phase I, all animals were adapted to the feeding schedule while both the running wheel and drinking tube were accessible ( $\mathrm{D}+\mathrm{R}$, Int condition). In Phase II, the drinking tube was removed so that rats 30 and 31 could only run (R, Int condition), while the door to the running wheel was closed so that rats 32 and 33 could only drink (D,Int condition). In Phase III, these conditions were reversed: rats 30 and 31 could only drink while rats 32 and 33 could only run. The $D+R$, Int condition was then reinstated for all animals in Phase IV. Daily sessions were 50 intervals in duration, and each animal received 25 food pellets per session.

In Phase $\mathrm{V}$, the discriminative stimulus was on at the beginning of each session and was extinguished when a rat had obtained 25 food pellets for 25 leverpresses. The stimulus remained off for the duration of each 1-h session and no further food was delivered. Both the running wheel and drinking tube were accessible during Phase V (D+R,Ext condition). In Phase VI, the D+R, Int condition was reinstated for all animals for seven sessions.

During Phases I through IV, separate counters recorded the number of licks and quarter wheel rotations occurring during intervals initiated with food (postfood intervals) and during intervals initiated without food (postomission intervals). The amounts of time spent drinking and running during each type of interval

Table 1

Sequence of Conditions and Number of Sessions Exposure for Each Rat

\begin{tabular}{ccccccc}
\hline Rat & Phase I & Phase II & Phase III & Phase IV & Phase V & Phase VI \\
\hline 30 & D+R, Int: 34 & R, Int: 13 & D, Int: 15 & D+R, Int: 16 & D+R, Ext: 18 & D+R, Int: 7 \\
31 & D+R, Int: 31 & R, Int: 15 & D, Int: 15 & D+R, Int: 15 & D+R, Ext: 16 & D+R, Int: 7 \\
32 & D+R, Int: 38 & D, Int: 13 & R, Int: 12 & D+R, Int: 13 & D+R, Ext: 13 & D+R, Int: 7 \\
33 & D+R, Int: 35 & D, Int: 11 & R, Int: 12 & D+R, Int: 13 & D+R, Ext: 17 & D+R, Int: 7 \\
\hline
\end{tabular}

Note-Letters indicate experimental conditions: $D+R$, both water and running wheel accessible; $D$, water only accessible; $R$, wheel only accessible; Int, intermittent schedule in effect; Ext, intermittent schedule not in effect. Numbers to right of condition indicate number of sessions' exposure. 
were also recorded. To measure drinking bouts, the appropriate cumulative timer was activated by licks that triggered the drinkometer, and the timer remained on until no licks had occurred for $.5 \mathrm{sec}$. Time spent running was measured similarly, except that the timer remained on until no quarter wheel turns had occurred for 1.0 sec: These values imposed lower bounds of 120 and $60 \mathrm{responses} / \mathrm{min}$, respectively, on the ranges of local rates that could be detected, and were empirically determined to be below the rates evinced by the animals.

In order to obtain information about the temporal distributions of responding during Phase VI, licks and quarter wheel rotations were distributed by a stepper to counters accumulating responses occurring in successive 10 -sec segments of postfood and postomission intervals.

During Phase $\mathrm{V}$, the numbers of responses and time spent responding in the presence and absence of the discriminative stimulus were recorded. The number of licks and quarter wheel rotations were also distributed by a stepper to four counters each, accumulating responses from successive 15-min segments of the session.

\section{RESULTS}

In addition to measures of overall rates and times spent drinking and wheel running, within-bout rates of these two activities were calculated by dividing the number of responses by the amount of time spent responding. These three measures are shown on three sets of axes for each animal in Figures 1 and 2.

In the top row of axes it can be seen that during Phase I all animals licked at higher overall rates than during habituation sessions, and that for all but rat 30 overall rates increased systematically across sessions of Phase I. The overall rate of licking by rat 30 did increase systematically across sessions of Phase III however, and it remained high during Phase IV. Overall rates for the other three animals during Phases II through IV varied about the terminal

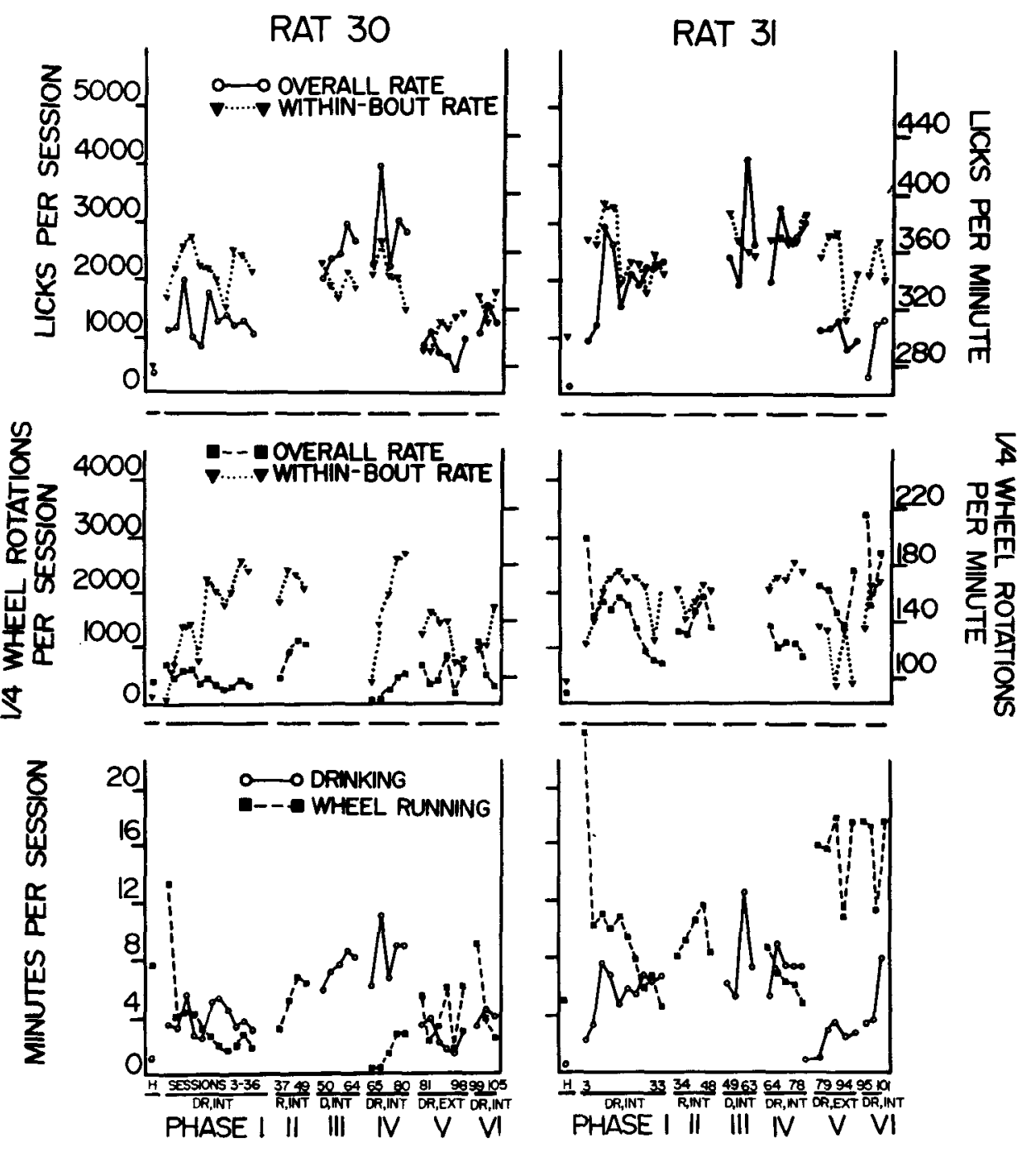

Figure 1. Overall rates (responses per session), within-bout rates (responses/minute spent responding), and minutes/session spent drinking and wheel running as functions of sessions over all phases of the experiment for rats 30 and 31. Data points represent arithmetic averages from three sessions except for the last point in each phase, which may represent two, three, or four sessions, depending on the number of sessions of exposure given an animal. Unconnected points on the left in each set of axes represent means from two habituation sessions. 


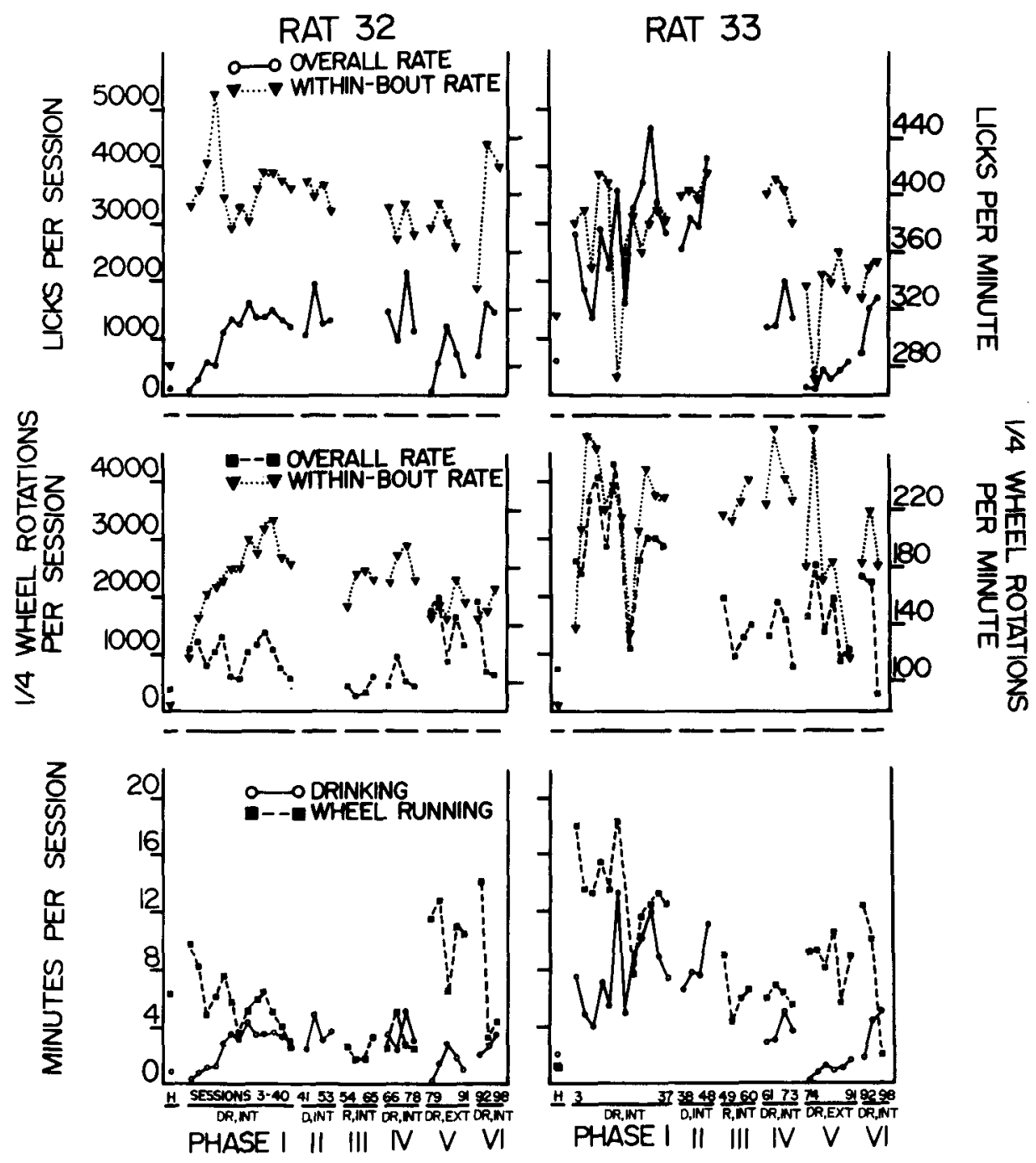

Figure 2. Overall rates (responses per session), within-bout rates (responses per minute spent responding), and minutes per session spent drinking and wheel running as functions of sessions over all phases of the experiment for rats 32 and 33 . For further explanation see Figure 1.

rates attained in Phase $I$. When the intermittent schedule was discontinued during Phase V, overall rates of licking decreased for all animals. Over the seven sessions of Phase VI, responding did not stabilize, but the trend was for overall rates and times to increase across sessions.

There was no systematic variation of within-bout lick rates (top row, dotted lines) during Phases I through IV, although within-bout rates did decrease for three animals during Phase $\mathrm{V}$ and increased again during Phase VI. Product-moment correlations of overall rates and times spent licking were .97 or better for all animals across all phases of the experiment.

In the second row of axes, it can be seen that, as with licking, overall rates of wheel running were higher during the first days of Phase I than during habituation sessions. However, in contrast to lick- ing, overall rates of running decreased for three of four animals, time spent running decreased for all animals (bottom row, dotted lines), and within-bout rates increased for two animals (second row, dotted lines) across sessions of Phase I. Rats 30 and 31 were exposed to the R,Int condition during Phase II, and in Figure 1 overall rates and times evinced by these animals were greater than those evidenced during the terminal sessions of Phase I. In Figure 2, it can be seen that rats 32 and 33 , who were exposed to the $\mathrm{R}$,Int condition during Phase III, tended to run at lower overall rates for less time than during the terminal sessions of Phase $\mathrm{I}$.

By the end of the D + R, Int condition of Phase IV, overall rates and times for three of four animals were comparable to those of Phase I, whereas data from rat 33 were comparable to those of the immediately preceding $\mathrm{R}$, Int condition. During Phase $\mathrm{V}$, time 
spent running increased for all animals, overall rates increased for two of four animals, and within-bout rates decreased for all animals relative to Phase IV. Again, data from Phase VI were quite variable, but the trend was for overall rates and times to decrease across sessions.

Although there is considerable variability in the overall data as presented in Figures 1 and 2, the proportions of responding occurring during postfood and postomission intervals over the last 10 sessions of Phases I through IV were quite stable. Table 2 presents the mean number of minutes per session spent drinking and wheel running during each type of interval over the last 10 sessions of Phases I through IV and the last 3 sessions of Phase VI. The table is arranged by condition rather than in chronological sequence for ease of comparison, and it provides two independent indices of the effects of food and no food on wheel running and drinking: Betweenresponse, within-interval comparisons can be made by reading along the rows, and within-response, between-interval comparisons can be made by reading down the columns. $t$ scores were calculated for the distributions of differences in time spent responding both between and within responses over the last 10 sessions of Phases I and IV $(\mathrm{df}=9)$ and the last 3 sessions of Phase VI ( $\mathrm{df}=2)$. For Phases II and III, $t$ scores were calculated within responses only over the last 10 sessions ( $\mathrm{df}=9$ ).

Between-response comparisons across rows show that all animals spent significantly more time drinking than wheel running during postfood intervals of Phases I and IV, and that all but rat 30 spent more time running than drinking during postomission intervals $(p<.05)$. Within-response comparison show that all but rat 30 did most of their drinking during postfood intervals of Phases I and IV, and that all animals did most of their running during postomission intervals $(p<.05)$. Although per- formance during Phase VI was not stable, rats 30 , 32 , and 33 did confirm the results of Phases $I$ and IV. Rat 31 did more running overall, emitting rates and times comparable to those of the immediately preceding D+R,Ext condition (see Figure 1). Consequently, more time was spent running than drinking during both types of intervals, although most drinking continued to occur during postfood intervals and most running continued to occur during postomission intervals.

The extent to which these results were due to competitive interactions between drinking and wheel running was assessed in Phases II and III, when either the drinking tube or running wheel was inaccessible. Rats 31 and 33, which did the most overall drinking and showed the clearest differentiation between drinking and running patterns in Phase I, continued to do most of their drinking during postfood intervals during the $D$,Int condition, although the difference was significant only for rat $33(p<.05)$. Rats 30 and 32 drank less overall, did not show as clearly differentiated running and drinking patterns in Phase I, and did a higher proportion of their drinking during postomission intervals than during postfood intervals in the $D$, Int condition. All animals continued to do most of their running during postomission intervals in the R, Int condition.

In Phase $\mathrm{V}$, we examined the effects of extinction on drinking and wheel running, both in terms of effects on overall "response strength" and in terms of the distribution of responding within a session. By the end of the second session of Phase V, all animals were collecting 25 food pellets for 25 leverpresses within the first 2 or $3 \mathrm{~min}$ of each session, and virtually no drinking or running occurred in the presence of the discriminative stimulus. In Figure 3, the overall rates of drinking and wheel running (in responses/minute) are plotted over successive 15-min segments of a session, averaged over the last three

Table 2

Time Spent Drinking (D) and Wheel Running (R) During Postfood and Postomission Intervals

\begin{tabular}{|c|c|c|c|c|c|c|c|c|}
\hline & \multicolumn{2}{|c|}{ Phase I } & \multicolumn{2}{|c|}{ Phases II and III } & \multicolumn{2}{|c|}{ Phase IV } & \multicolumn{2}{|c|}{ Phase VI } \\
\hline & D & $\mathrm{R}$ & $\mathrm{D}$ & $\mathbf{R}$ & $\mathrm{D}$ & $\mathbf{R}$ & D & $\mathbf{R}$ \\
\hline & \multicolumn{8}{|c|}{ Rat 30} \\
\hline $\begin{array}{l}\text { PF } \\
\text { PO }\end{array}$ & $\begin{array}{l}1.07+* \\
2.15\end{array}$ & $\begin{array}{c}.20 \\
1.85^{*}\end{array}$ & $\begin{array}{l}2.54^{*} \\
5.44\end{array}$ & $\begin{array}{l}1.32 \\
3.69^{*}\end{array}$ & $\begin{array}{l}3.24 \dagger \\
3.24\end{array}$ & $\begin{array}{l}.45 \\
1.62 \dagger^{*}\end{array}$ & $\begin{array}{l}1.90 \dagger \\
2.51\end{array}$ & $\begin{array}{c}.59 \\
1.68 *\end{array}$ \\
\hline \multicolumn{9}{|c|}{ Rat 31} \\
\hline $\begin{array}{l}\text { PF } \\
\text { PO }\end{array}$ & $\begin{array}{c}5.44 \dagger^{*} \\
.98\end{array}$ & $\begin{array}{c}.23 \\
5.30 \dagger^{*}\end{array}$ & $\begin{array}{l}4.85 \\
3.27\end{array}$ & $\begin{array}{l}2.74 \\
7.24\end{array}$ & $\begin{array}{l}5.77 \dagger^{*} \\
1.67\end{array}$ & $\begin{array}{l}1.01 \\
4.88+*\end{array}$ & $\begin{array}{r}1.67 \\
.25\end{array}$ & $\begin{array}{l}5.87 \\
9.40\end{array}$ \\
\hline \multicolumn{9}{|c|}{ Rat 32} \\
\hline $\begin{array}{l}\text { PF } \\
\text { PO }\end{array}$ & $\begin{array}{l}1.64 \dagger^{*} \\
1.41\end{array}$ & $\begin{array}{l}.44 \\
3.32 \dagger^{*}\end{array}$ & $\begin{array}{l}1.68 \\
2.12\end{array}$ & $\begin{array}{c}.24 \\
1.60^{*}\end{array}$ & $\begin{array}{l}2.85 \dagger^{*} \\
1.46\end{array}$ & 2.52 & $\begin{array}{r}2.28 \\
.90\end{array}$ & $\begin{array}{r}.45 \\
3.59\end{array}$ \\
\hline \multicolumn{9}{|c|}{ Rat 33} \\
\hline $\begin{array}{l}\text { PF } \\
\text { PO }\end{array}$ & $\begin{array}{c}9.87 \dagger^{*} \\
.11\end{array}$ & $\begin{array}{l}2.64 \\
9.53 \dagger^{*}\end{array}$ & $\begin{array}{c}9.21 * \\
.13\end{array}$ & $\begin{array}{c}.96 \\
5.23^{*}\end{array}$ & $\begin{array}{c}4.08 \dagger * \\
.21\end{array}$ & $\begin{array}{l}1.09 \\
3.34 \uparrow^{*}\end{array}$ & $\begin{array}{c}4.33^{*} \\
.06\end{array}$ & $\begin{array}{r}.95 \\
6.53\end{array}$ \\
\hline
\end{tabular}

Note-Numbers represent average minutes per session over the last 10 sessions of Phases I through IV, and the last 3 sessions of 


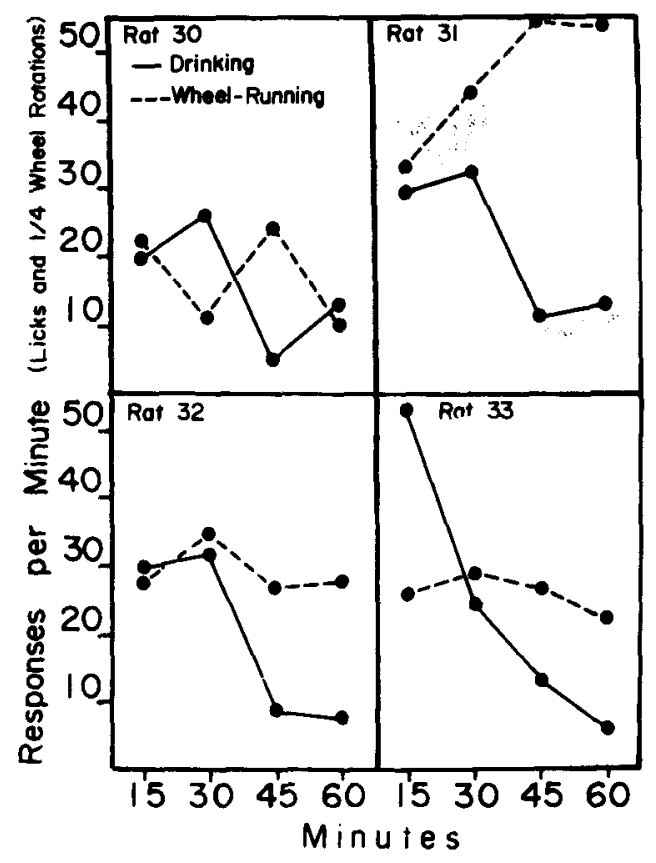

Figure 3. Overall rates of drinking and wheel running (responses/ minute) as functions of session time during Phase $V$. Data points represent arithmetic averages from the last three sessions.

sessions. All animals did most of their drinking within the first 30 min of a session, while wheel running was evenly distributed throughout the session for three of four animals and increased with time for rat 31.

In Phase VI, the D+R, Int condition was reinstated for seven sessions in order to obtain information about the temporal distributions of responding within each type of interval. Casual observation had suggested that after receiving a food pellet, the animals would remain at the food tray for periods of time much longer than required to ingest the pellet, but that when no food was delivered the animals would immediately leave the vicinity of the food tray and engage in other activities.

Figure 4 presents the probabilities of drinking and wheel running as functions of postevent time in postfood and postomission intervals over the last three sessions of Phase VI. Probabilities were calculated by determining the mean within-bout interresponse time for each type of interval in each session, multiplying by the number of responses occurring in each 10 -sec bin, and finally dividing the quotient by the amount of time available in each bin and averaging across sessions. These calculations were performed because overall rate measures do not provide an adequate picture of how the animals distribute their time between responses.

In general, the distributions in Figure 4 verify our casual observations. Rats 31,32 , and 33 did virtually no drinking or running during the first $10 \mathrm{sec}$ of postfood intervals, whereas the probabilities of running during the first $10 \mathrm{sec}$ of postomission intervals were relatively high. This pattern is also evident for rat 30, aithough absolute levels of responding were quite low overall.

A significant question is whether the data from Phase VI in Figure 4 are representative of distributions from earlier phases: absolute levels of responding, particularly for rat 31 , were somewhat different from those evinced in earlier phases. Since, throughout the experiment, within-response comparisons were little affected by absolute levels of responding, we are fairly confident that the distributions are representative.

\section{DISCUSSION}

Simple periodic food schedules may have at least two different effects. First, they may increase the probability of behavior that normally occurs in "food-getting" situations. Second, periodic food presentations may serve as time markers initiating intervals that must elapse before food again becomes available, and under stimulus conditions signaling the temporary absence of food animals may seek alternate sources of reinforcement (cf. Hearst \& Jenkins, 1974; Staddon, 1972; Staddon \& Simmelhag, 1971). Thus, periodic food schedules may exert differential control on several types of behavior, some determined by the presence of food in the overall situation, others determined by the absence of food at particular times within that situation. Behavior of the former sort may be said to be food-bound, while that of the latter sort is not.

Drinking appears to be a food-bound activity.

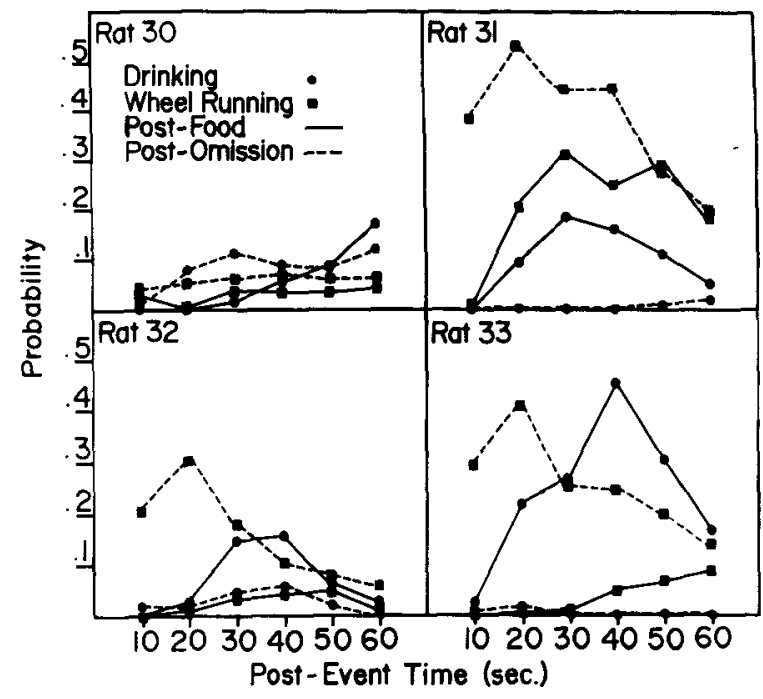

Figure 4. Probabilities of drinking and wheel running (time spent responding/total time available) as functions of postevent time in Phase VI. Data points represent arithmetic averages from the last three sessions. 
It is well established that rats tend to drink immediately before or after eating (Kisseleff, 1969). Scheduleinduced drinking has been successfully maintained only with food reinforcement, and then only with some types of food (Falk, 1967; Freed, 1971; Stricker \& Adair, 1966; but see Atrens, 1973, who reports drinking induced, but not maintained, by ICS reinforcement). Drinking tends to occur immediately after eating unless artificial constraints are imposed (cf. Flory \& O'Boyle, 1972; Gilbert, 1974; Stein, 1964). The overall rate of drinking varies directly with the overall density of food in the situation, as determined by rate and magnitude of food reinforcement (Couch, 1974; Flory, 1971; Hawkins et al., 1972). Drinking subsides very rapidly when the food schedule is discontinued (Ponicki \& Thompson, 1972), and when stimuli that have been paired with food are occasionally presented in lieu of food, drinking during intervals initiated by the stimuli alone is greatly attenuated (Porter \& Kenshalo, 1974; Rosenblith, 1970; Wuttke \& Innis, 1972). When food was presented on a percentage reinforcement schedule in which a stimulus that had never been paired with food was occasionally presented, five of six rats failed to drink at all during intervals initiated with the stimulus (Allen, Porter, \& Arazie, 1975). In the present experiment, drinking increased during adaptation to the feeding schedule and subsided when the intermittent schedule was discontinued. Drinking occurred primarily during postfood intervals, and in the $\mathrm{D}+\mathrm{R}$, Ext condition, drinking decreased with time since eating.

In contrast to drinking, wheel running does not appear to be food-bound. It has been successfully maintained with water reinforcement for thirsty rats (King, 1974). With food reinforcement, the rate of wheel running decreases as food rate increases (Staddon, 1977). When both water and a running wheel are concurrently available, drinking follows eating, while running follows drinking (Segal, 1969; Staddon \& Ayres, 1975). Event records exhibited by Levitsky and Collier (1968) for rats leverpressing on a variable-interval schedule for food indicate that drinking occurred only after eating, while running showed no such constraints and often occurred after unreinforced leverpresses. Similarly, Smith and Clark (1974) exposed rats to a schedule in which only interresponse times of greater than a specified duration were reinforced and found that drinking closely followed eating, while running followed unreinforced leverpresses. In the present experiment, wheel running decreased during adaptation to the feeding schedule and increased when the intermittent schedule was discontinued. Wheel running occurred primarily during postomission intervals, and in the $\mathrm{D}+\mathrm{R}$, Ext condition wheel running did not vary with time elapsed since eating.

That rat 30 did most of his drinking during post- omission intervals in Phase I and that both rat 30 and rat 32 did most of their drinking during postomission intervals during the $D$, Int condition would appear to contradict this interpretation. However, these results might be seen as "omission effects." Staddon (1974) has argued that food is a more valuable, and hence more "salient," stimulus for hungry animals than is a neutral time marker, and that temporal control by the latter might therefore be "overshadowed" by the former. That is, animals respond to short postomission times as to long postfood times, such that after presentation of an omission stimulus animals tend to continue with activities they were engaged in immediately prior to stimulus presentation. If, in the present experiment, postomission times are considered equivalent to long postfood times, then more wheel running than drinking would be expected to occur during postomission intervals, since previous studies indicate that wheel running occurs at later postfood times than does drinking. However, if the initiation of drinking were to be delayed, or if an animal tended to take particularly long drinks, then postfood drinking might carry over into postomission intervals. To the extent that drinking does carry over, postomission running might be suppressed by response competition.

That rats 30 and 32 did little drinking or wheel running at short postfood times is consistent with the notion that some postpellet activity was displacing them, but, since we did not systematically observe the animals, we can only speculate about the nature of such activity. In an observational study in which rats were given food pellets once every $90 \mathrm{sec}$, it was found that the animals would lick and gnaw at the food tray or remain immobile in front of it for up to $30 \mathrm{sec}$ after each pellet delivery (Penney \& Neuringer, Note 1). Casual observation suggests that similar activity occurred in the present experiment.

In addition to providing evidence that drinking and wheel running may be differentiable in terms of "food-boundedness," our data are consistent with the hypothesis that drinking is schedule induced while wheel running is not. Wheel running subsided during adaptation to the feeding schedule and increased during extinction, while drinking increased during adaptation and subsided during extinction. It should be noted, however, that water was always available in home cages, while access to the running wheel could be had only during experimental sessions. Thus, the rats were effectively running deprived, and such deprivation might be expected to produce relatively high rates of running during extinction. On the other hand, procedures which have effectively induced drinking have failed to demonstrate the induction of wheel running, as described in the introduction.

If drinking and wheel running may be functionally 
differentiable, what of other adjunctive behavior? We have already noted that escape and aggression vary bitonically with food rate, a pattern different from both that for drinking and that for wheel running. Furthermore, these two activities are clearly schedule induced, but are probably not foodbound (cf. Brown, 1975; Gentry \& Schaeffer, 1969; Huston \& DeSisto, 1971). When food is the reinforcer for hungry rats, both aggression (Knutson \& Schrader, 1975) and escape (Penney \& Neuringer, Note 1) occur after drinking and are initiated at later postfood times than drinking, even when water is not available.

Other reported activities that appear similar to each other but different from other adjunctive behavior are the ingestion of wood shavings by chimpanzees (Villareal, Note 2) and wood gnawing by rats (Killeen, 1975). The temporal dynamics of these activities appear to be more like those of drinking and less like those of wheel running, aggression, or escape. While the extent to which these activities are food-bound is unclear, Villareal reported that his chimps would alternate between drinking and pica, while Killeen reported that the introduction of a wood block to gnaw reduced drinking substantially and that gnawing tended to occur before drinking.

In sum, the present paper challenges the assumption that interim activities occurring during intermittent reinforcement may be included in a single class of adjunctive behaviors which have comparable functional properties. It strongly suggests that future research might profitably examine in greater detail the causal factors for a variety of schedulerelated activities.

\section{REFERENCE NOTES}

1. Penney, J., \& Neuringer, A. J. The interaction of scheduleinduced polydipsia and escape. Paper presented at the meeting of the Western Psychological Association, San Francisco, 1974.

2. Villareal, J. G. Schedule-induced pica. Paper presented at the meeting of the Eastern Psychological Association, Boston, 1967.

\section{REFERENCES}

Allen, J. D., Porter, J. H., \& Arazie, R. Schedule-induced drinking as a function of percentage reinforcement. Journal of the Experimental Analysis of Behavior, 1975, 23, 223-232.

Atrens, D. M. Schedule-induced polydipsia and polyphagia in non-deprived rats reinforced by intercranial stimulation. Learning and Motivation, 1973, 4, 320-326.

BRown, T. G. Aversive properties of briefly presented stimuli: Escape behavior induced by second-order schedules of reinforcement. Unpublished doctoral dissertation, University of Maine, 1975.

Brown, T. G., \& FloRY, R. K. Schedule-induced escape from fixed-interval reinforcement. Journal of the Experimental Analysis of Behavior, 1972, 17, 395-403.

Couch, J. V. Reinforcement magnitude and SIP: A reexamination. Psychological Record, 1974, 24, 559-562.

FALK, J. L. Schedule-induced polydipsia as a function of fixed interval length. Journal of the Experimental Analysis of Behavior, 1966, 9, 37-39.
FaLk, J. L. Control of schedule-induced polydipsia: Type, size, and spacing of meals. Journal of the Experimental Analysis of Behavior, 1967, 10, 199-206.

FALK, J. L. Theoretical review: The nature and determinants of adjunctive behavior. Physiology and Behavior, 1971, 6, 577-588.

FLORY, R. K. Attack behavior as a function of minimum interfood interval. Journal of the Experimental Analysis of Behavior, $1969,12,825-828$.

FLoRY, R. K. Control of schedule-induced polydipsia: Frequency and magnitude of reinforcement. Learning and Motivation, 1971, 2, 215-227.

FloRY, R. K.. \& O'Boyle, M. K. Effects of limited water availability on schedule-induced polydipsia. Physiology and Behavior, 1972, 8, 147-149.

Freed, E. X. Schedule-induced polydipsia with nutritive and non-nutritive reinforcers. Psychonomic Science, 1971, 23, $367-368$.

Gentry, W. D., \& Schaeffer, R. W. The effect of FR response requirement on aggressive behavior in rats. Psychonomic Science, 1969, 14, 236-238.

Gilbert, R. M. The ubiquity of schedule-induced polydipsia. Journal of the Experimental Analysis of Behavior, 1974, 21, 227-284.

Hawkins, T. D., Schrot, J. F., Githens, S. H., \& Everett, P. B. Schedule-induced polydipsia and alcohol ingestion. In R. M. Gilbert \& J. D. Keehn (Eds.), Schedule effects: Drugs, drinking, and aggression. Toronto: University of Toronto Press, 1972.

Hearst, E., \& Jenkins, H. M. Sign tracking: The stimulusreinforcer relation and directed action. Austin, Tex: Psychonomic Society, 1974.

Huston. J. B., \& DeSisto, M. J. Interspecies aggression during FR hypothalamic self-stimulation in rats. Physiology and Behavior, 1971, 7, 353-357.

Killeen, P. On the temporal control of behavior. Psychological Review, 1975, 82, 89-115.

KING, G. D. Wheel running in the rat induced by fixed-time presentation of water. Animal Learning \& Behavior, 1974, 2, 325-328.

KIssileFF, H. R. Food-associated drinking in the rat. Joumal of Comparative and Physiological Psychology, 1969, 67, 284-300.

Knutson, J. F., \& Schrader, S. D. A concurrent assessment of schedule-induced aggression and schedule-induced polydipsia in the rat. Animal Learning \& Behavior, 1975, 3, 16-20.

Levitsky, D., \& Collier, G. Schedule-induced wheel running. Physiology and Behavior. 1968, 3, 571-573.

Ponicki, E., \& Thompson, T. The effects of extinction of food-reinforced responding on schedule-induced polydipsia. Psychonomic Science, 1972, 28, 5-6.

Porter, J. H., \& Kenshalo, D. R. Drinking following omission of reinforcement in the rhesus monkey. Physiology and Behavior, 1974, 12, 1075-1077.

Rosenblith, J. Z. Polydipsia induced in the rat by a second-order schedule. Journal of the Experimental Analysis of Behavior, 1970, 14, 139-144.

SEGAL, E. F. The interaction of psychogenic polydipsia with wheel running in rats. Psychonomic Science, 1969, 14, 141-142.

Segal, E. F., Oden, D. L., \& Deadwyler, S. A. Determinants of polydipsia. IV: Free reinforcement schedules. Psychonomic Science, 1965, 3, 11-12.

SkINNER, B. F., \& Morse, W. H. Concurrent activity under fixed-interval reinforcement. Journal of Comparative and Physiological Psychology, 1957, 50, 279.281.

Smith, J. B., \& ClaRK, F. C. Intercurrent and reinforced behavior under multiple spaced-respond ing schedules. Journal of the Experimental Analysis of Behavior, 1974, 21, 445-454.

Staddon, J. E. R. Temporal control and the theory of reinforcement schedules. In R. M. Gilbert \& J. R. Millenson (Eds.), Reinforcement: Behavioral analyses. New York: Academic Press, 1972.

Staddon, J. E. R. Temporal control, attention, and memory. Psychological Review, 1974, 81, 375-391. 
Staddon, J. E. R. Schedule-induced behavior. In W. K. Honig \& J. E. R. Staddon (Eds.), Handbook of operant behavior. Englewood Cliffs, N.J: Prentice-Hall, 1977.

Staddon. J. E. R., \& AYREs, S. Sequential and temporal properties of behavior induced by a schedule of periodic food delivery. Behaviour, 1975, 54, 26-49.

Staddon, J. E. R., \& Simmelhag, V. The superstition experiment: A reexamination of its implications for the principles of adaptive behavior. Psychological Review, 1971, 78, 3-43.

STEIN, L. Excessive drinking in the rat: Superstition or thirst? Journal of Comparative and Physiological Psychology, 1964, 58. 237.242 .
Stricker, E. M., \& Adair, E. R. Body fluid balance, taste, and post-prandial factors in schedule-induced polydipsia. Journal of Comparative and Physiological Psychology, 1966, 62. 449-454.

WutTKE, W., \& InNIs, N. K. Drug effects upon behavior induced by second-order schedules of reinforcement: The relevance of ethological analyses. In R. M. Gilbert \& J. D. Keehn (Eds.), Schedule effects: Drugs, drinking, and aggression. Toronto: University of Toronto Press, 1972.

(Received for publication June 22, 1976; revision accepted April 20, 1977.) 